\title{
A POLÍtica EMPRESARIAL: A RESPONSABILIDADE SOCIAL COMO MECANISMO DE SEGURANÇA ${ }^{\star}$
}

\author{
Sonia Moreira França $\star \star$ \\ Fernando Zanetti $\star \star \star$
}

\begin{abstract}
Resumo
Neste ensaio, tomamos como problema as ações da política empresarial no Brasil, em especifico a politica de responsabilidade social das empresas, por entender que existe nessa iniciativa um status de inovação tecnológica que precisa ser interrogado, pois se inscreve no interior de uma racionalidade que objetiva o governo das populações e tem como instrumento técnico, para realizar esse fim, uma sociedade controlada por mecanismos de segurança. Para tanto, partimos da análise de três procedimentos efetivados por alguns projetos sociais desenvolvidos por empresas brasileiras - a pesquisa cientifica, o protagonismo juvenile a metodologia participativa. A referência de análise são textos de diversas naturezas, veiculados por esses projetos e disponíveis ao acesso público.
\end{abstract}

Palavras-chave: politica empresarial; controle social; mecanismos de segurança.

\section{The BUSINESS POLITICAL: THE SOCIAL RESPONSIBILITY AS SECURITY MECHANISM}

\begin{abstract}
In this research we discuss some political business actions, in Brazil, in particular the politics of social responsibility of companies, understanding that there is in this initiative a technological innovation status that needs to be questioned. Therefore it refers to the rationality that aims the management of populations. It has as technical device to achieve this a society controlled by security mechanisms. We take therefore as the axis of analysis three procedures enforced by some social projects developed by Brazilian companies - the scientific research, the juvenile protagonism and the participative methodology. The reference to the analysis are texts of many kinds from these projects and available to public access.
\end{abstract}

Keywords: corporate politics; social control; security mechanisms.

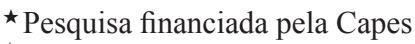

$\star \star$ Professora colaboradora do curso pos-graduação em Psicologia da Unesp. Endereço: Avenida Dom Antonio, 2100. CEP: 19806-900 Assis - SP, Brasil. E-mail: soniamfranca@uol.com.br

$\star \star \star$ Aluno do curso de pos-graduação em Psicologia da Unesp. Nível: doutorado. Endereço: Avenida Dom Antonio, 2100. CEP: 19806-900 Assis - SP, Brasil.

E-mail: fernandozanetti@hotmail.com
} 


\section{INTRODUÇ̃̃o}

Este ensaio objetiva problematizar a política empresarial no Brasil, em específico àquela orientada por uma prática denominada responsabilidade social das empresas, pois, em nosso entender, essa prática inscreve no mundo social um conjunto de procedimentos que incitam, apoiam e legitimam um tipo de racionalização do exercício de governo que se efetiva como um instrumento crítico da realidade, ou seja, um esquema regulador da prática governamental: o liberalismo. Para tanto, tomamos como referência as análises de Michel Foucault (2008a) sobre o processo de governamentalização ${ }^{1}$ da vida na atualidade, ou seja, um tipo de ação governamental que tem a população como objeto de técnica de governo e nos dispositivos de segurança seus mecanismos de sustentação.

Se nossa preocupação é a de evidenciar esse enunciado de responsabilidade social das empresas é por entender que a emergência de uma prática estabelece relações diretas com uma série de instituições, com as urgências políticas e suas formas de regulamentação social e com as exigências econômicas vigentes na sociedade em que vivemos. Como diria Foucault (1979, p. 3-4) em seu texto Verdade e Poder, não são simplesmente novas descobertas, mas a emergência de um novo regime no discurso e na ordem do saber, de uma política de enunciado científico. O que está em questão é o que rege esse discurso, os efeitos de poder e verdade que circulam entre seus enunciados, pois para o autor, a verdade é deste mundo, não existe fora dos efeitos de poder próprios do jogo enunciativo, dos "modos como sanciona uns e outros, as técnicas e os procedimentos que são valorizados para a obtenção da verdade; o estatuto daqueles que têm o encargo de dizer o que funciona como verdadeiro" (FOUCAULT, 1979, p. 12). A tarefa, então, é a de evidenciar as relações de força presentes e em operação nessa nova tecnologia: as ações de responsabilidade social das empresas, como desenvolve suas estratégias e táticas e seus domínios de objeto.

Se tomarmos em consideração o Relatório do Instituto de Cidadania Empresarial, localizado na cidade de São Paulo, ele se nos apresenta como uma estratégia de ação empresarial que tem como meta orientar e regular a "participação da iniciativa privada de forma pró-ativa e estruturada na busca de soluções para a questão social" (INSTITUTO DE CIDADANIA EMPRESARIAL, 2004, p. 6). Essa modalidade de intervenção no mundo social se propõe a: "Ser referência em práticas sociais e influenciar, por meio de projetos e programas bem sucedidos, a formulação, execução e monitoramento de políticas públicas" (INSTITUTO DE CIDADANIA EMPRESARIAL, 2004, p. 6).

Frente a essa prática social, ao considerar algumas de suas proposições e de seus interesses específicos, perguntamos: a que relações de poder essa prática social responde ao fomentar suas ações?

Podemos considerar algumas estratégias e táticas que a política empresarial de responsabilidade social propõe aos projetos sociais. $\mathrm{O}$ empresariado investe em um projeto dessa natureza, por entender que este oferece certa resolutividade a vários problemas que afligem a sociedade atual. Em primeiro lugar, a proximi- 
dade inevitável que os centros urbanos proporcionam entre os pobres e os ricos intensifica os enfrentamentos e, assim, são levados a observar e a conviver com as desigualdades sociais. Em resposta a essa proximidade, os projetos sociais podem trazer alguma "solução de compromisso" para esses confrontos, domesticando-os. Em segundo, por tornar a efetivação do projeto mais ágil, pois não é necessário passar pelas instâncias de controle social do Estado, nem por seus entraves burocráticos, é possível efetivar um livre mercado de oferta e demanda. Em terceiro, quem determina como e onde serão gastos os recursos financeiros são os próprios empresários, uma vez que os projetos são financiados e realizados pela iniciativa privada, e a maneira como será usado o recurso depende exclusivamente da lógica de economia de capital. Portanto, as forças que estão em jogo são as do livre comércio de mercadorias, sejam elas as coisas, sejam os homens. Em quarto, além de realinhar as relações de vizinhança entre ricos e pobres, a política empresarial ainda pode gerar lucros dessa parceria com o Estado, em sua tarefa de regular as flutuações da produção e da circulação das riquezas. Esse lucro é possível devido às novas técnicas de venda de produtos, as quais trazem a ideia de consumo responsável e sustentável e a criação da noção de responsabilidade social das empresas. Em quinto, o fato de o projeto social tornar-se instrumento de barganha política ${ }^{2}$, um "palanque" que pode ser usado por políticos, em troca de favores e outras concessões do governo, como, por exemplo, a isenção fiscal.

Se essas táticas levam o mercado de capitais a investir no mercado da pobreza, de maneira especial, devemos agora evidenciar as estratégias e os procedimentos que este incita, econômica e politicamente, para o controle social da miséria. Nessa perspectiva, perguntamos: quais estratégias são articuladas pela política empresarial de responsabilidade social, para responder a essa demanda das práticas do capital? Quais procedimentos e técnicas essas estratégias instituem ou promovem?

\section{Procedimentos de afirmação do Capital}

\subsection{Uma mudança de foco nos critérios de ação governamental}

Esta estratégia de trabalho das relações de poder, encontrada a partir da política empresarial, refere-se às mudanças de foco com relação às análises das forças produtivas do capitalismo. Para as novas tecnologias de governo (FOUCAULT, 2008a), o que está em jogo, nas estratégias de gestão da riqueza e da pobreza, é a positividade e a racionalidade das forças produtivas para a expansão da riqueza, isto é, diz respeito às flutuações dos limites toleráveis no interior das curvas de normalidade econômica imanentes aos fenômenos da população; estimular os índices de produção, de natalidade, dirigir os fluxos populacionais férteis e intensificar a utilidade dos indivíduos etc. são algumas dessas estratégias.

\subsection{1- O binômio escassez/abundância das riquezas}

Essa mudança de foco analítico gera duas situações. Primeira, o capital empresarial investe na realização de um tipo de ação que intervém diretamente nesse elemento da realidade, qual seja: o empresariado passa a realizar ações que 
afetam diretamente os mecanismos os quais salientam as diferenças na distribuição das riquezas; e, principalmente, objetiva a intervir nas lutas entre as estratégias de poder e as estratégias de enfrentamento e suas condições de rebelião.

Como diz Foucault (1995a, p. 234-235), as lutas hoje precisam ter como posição estratégica de enfrentamento atacar toda forma de poder que se aplica à vida cotidiana imediata e quer dizer quem somos nós. São lutas transversais, pois não se limitam a um país e têm por objetivo os efeitos de poder. São lutas imediatas contra o governo da individualização, pois se voltam contra as instâncias de poder que se exercem sobre as ações dos indivíduos; são lutas que questionam o estatuto do indivíduo, tanto no que diz respeito ao que o faz voltar-se para si mesmo, a uma identidade, quanto ao que o separa dos outros. São lutas contra os privilégios do saber e suas relações com o poder, como funciona, como circula, o que legitima. Ou seja, a luta contra as formas de subjetivação que integram uma forma política a uma tecnologia de poder pastoral, que tanto pode ser exercida pelo Estado, como por empreendimentos privados, e tem como meta uma participação na vida espiritual (modos de viver, exame e correção da consciência); no trabalho de salvação (riqueza suficiente, saúde, padrão de vida, segurança etc.), e na produção da verdade (o desenvolvimento de um saber sobre o homem, tanto globalizador e quantitativo - a população, quanto analítico - o indivíduo).

Confrontar a história do presente não significa libertar a verdade do poder, mas trazer à vista seus interesses, sua fabricação, as peças que a constituem em um plano geral de modelo das formas de organização das atividades humanas eficazes para o controle dos indivíduos e de suas eventuais transformações. É justamente neste elemento de realidade que as ações da responsabilidade social das empresas concentram a base de sua intervenção.

Para que este operador funcione de modo eficaz, o que se considera, nesse investimento, é como manter o que Foucault (2008a) denomina de um índice de segurança entre a escassez e a abundância, no interior de limites social e economicamente viáveis, e ao redor de uma média concebida como aceitável para um funcionamento social dado, a fim de evitar rebeliões. O que se enuncia é a ação de controles reguladores que inserem o fenômeno - escassez e abundância - na série de acontecimentos prováveis,que incorporam a ordem dos cálculos e custos nas relações de poder, esboçando uma outra distribuição das coisas e dos homens: o custo da escassez e o custo da abundância não se movimentam no mesmo ritmo ou na mesma direção; portanto, faz-se necessário criar mecanismos de segurança que introduzam modificações nesse elemento de realidade, alterando o destino da população. Enfim, o que está em jogo é como otimizar os elementos que compõem a população, esse conjunto complexo produzido na circulação de homens e coisas.

No caso da política empresarial, o que se lhe apresenta como problema é: como se apoiar em dados materiais específicos, não totalizáveis, pois vários são os objetos econômicos para assegurar o desenvolvimento econômico máximo, organizar sua circulação, suprimir seus aspectos perigosos, maximizar ou 
reduzir o consumo etc., ou seja, como gerir essas séries indefinidas e abertas (de circulação, de acontecimentos, de unidades que se acumulam), que só podem ser controladas pelo cálculo das probabilidades ?

Nessa perspectiva, os mecanismos reguladores das flutuações entre a pobreza e a riqueza enunciam um novo propósito para maximizar as positividades dos mercados de capital: a responsabilidade social dos fluxos econômicos. Mas como inscrever esse campo moral no domínio dos cálculos econômicos?

Em primeiro lugar, no campo da atitude crítica: com os processos de globalização e a circulação intensa de bens de capital, crescem as críticas à função do Estado e às racionalidades por ele instituídas, seja por estas não cumprirem com suas obrigações de regular os fluxos econômicos predatórios, seja por seus excessos de intervenção nos mecanismos de regulação. Em consequência, o que se institui como objeto de análise crítica é uma prática refletida de governo e as racionalidades por ela produzidas.

Existe, por exemplo, um discurso em evidência, para quem o Estado é incompetente e o verdadeiro responsável pelas condições de pobreza da população. Ao observar as fraquezas do Estado, a ineficiência de seus métodos e técnicas, no controle da população, evidencia-se os problemas sociais. Esse acontecimento expõe que o Estado de Bem-Estar Social tem seus limites no que diz respeito à governança do lucro e das condições da pobreza, apesar de seu raio de ação ser aberto e complexo. Se a função do Estado é administrar os limiares das curvas de normalidade da riqueza e da miséria, como enfrentar o lucro e agregar valor à miséria? Como regular essa zona cinza de interesses em conflito? Como governar?

Em segundo lugar, a política de responsabilidade social investe em ações que intensifiquem a articulação entre as diversas instituições disponíveis no campo social, tais como o Direito, a Educação, as instituições de Saúde etc. Para tanto, a política de responsabilidade social-empresarial engendra múltiplas articulações, em sua parceria com o Estado, na arte de governar, tanto para intensificar os processos de subjetivação cada vez mais heterogêneos e complexos a partir dos quais o homem se constituirá como sujeito, quanto para agir nas flutuações dos efeitos do capital sobre os destinos da população. Por conseguinte, entre a escassez e a abundância dos processos constitutivos da vida cotidiana, há uma série de curvas de normalidade econômica, social e subjetiva gerida no interior de diversas frentes institucionais que delimitam as condições possíveis de miséria e de riqueza.

\subsection{2 - O desempenho dos indivíduos}

A segunda situação que o desvio analítico engendra com relação aos critérios da ação governamental, no que concerne às análises das forças produtivas do capitalismo, acontece no momento em que as desigualdades econômicas deixam de ser um problema de exploração e contradição sociais, tornando-se um problema da ordem de desempenho dos indivíduos. O que isso quer dizer? Que existe um tipo de racionalidade política muito específica, implicada no exercício de poder de Estado, no que tange ao governo das condutas dos homens, o qual Foucault (1990; 1995a) 
denominará tecnologias de si. Para o autor, não é possível problematizar o Estado moderno - uma forma política de um poder que atua como um marco jurídico da unidade -, sem considerar as técnicas de poder orientadas aos indivíduos e interessadas em dirigi-los de maneira contínua e permanente - as técnicas de individuação, um tipo de poder pastoral, cuja função é cuidar da vida de todos e de cada um.

Importante ressaltar que interrogar os modos de produção das tecnologias de si, não requer o mesmo aparato material que a produção dos objetos, pois muitas vezes estão invisíveis e relacionadas com as técnicas para dirigir a conduta dos outros. Há nessa produção uma relação de responsabilidade, tanto do destino da população, como de cada um em particular, que exige, além da obediência, a manifestação do que se é em atos de verdade. O que isso quer dizer? Manifestar a verdade é afirmar a adesão a essa verdade; é explicitar as maneiras de dirigir o exame da consciência e aderir às práticas de correção e de obediência em que se engaja.

De acordo com Foucault (1990; 1997), as diversas formas de governo dos indivíduos determinam diferentes modos de constituição de um sujeito racional e normal; diferentes modos de objetivação do sujeito em saberes e diferentes modos de efetuação das relações de poder como um domínio de relações estratégicas entre indivíduos ou grupos que têm como alvo a conduta do outro. Trata-se de um tipo de técnica voltada para a formação de si, isto é, para a formação de um tipo de ciência que aprimore os jogos de verdade com técnicas muito específicas, a partir das quais o homem procurará entender a si mesmo, refletir sobre os modos de vida e de como regular sua conduta.

Esse acontecimento histórico, a emergência das Ciências Humanas, faz passar o homem para o lado dos objetos científicos, tornando-o um objeto de saber possível. Os processos de objetivação que transformam o ser humano em sujeito se orientam no interior de várias práticas: a) os modos de investigação que tomam em consideração o sujeito que trabalha, como a economia, a análise das riquezas; as investigações que têm como problema o sujeito que fala, como a linguística, a gramática; e aquelas que objetivam o homem enquanto ser vivo, como a biologia, a história natural etc. b) os processos de objetivação que intensificam procedimentos racionais de campos identitários para os indivíduos - as práticas divisoras do sujeito, tanto no interior de si mesmo como em sua relação com os outros homens - a razão, a emoção; a mente, o corpo; o doente, o sadio, o delinquente etc. c) as práticas em que o ser humano se reconhece como sujeito da sexualidade. Esses diferentes modos de objetivação e subjetivação do ser humano, em nossa cultura, ora o inscrevem em categorias universais, totalizando-o, ora multiplicam as flutuações de seus lugares de enunciação identitária, nas curvas de normalidade.

Frente a esse conjunto de práticas, podemos entender como Foucault (2004, p. 1) insiste na afirmação de que há "alguma coisa perturbadora no princípio do cuidado de si" e que as lutas hoje passam por interrogar as práticas a partir das quais o indivíduo constitui a si mesmo como sujeito moral de suas próprias ações, pois do ponto de vista desse operador em análise, o critério de avaliação para identificar o sujeito nas curvas de normalidade econômica será constitutivo das 
condições de desenvolvimento de capital humano de cada indivíduo, ou seja, a consciência da originalidade do indivíduo. Uma tática em operação bem diferente do que Foucault (1995b) dirá das práticas de si, que se referem ao domínio da ética e das práticas de liberdade: dar a si mesmo uma forma, ser artífice de si próprio, tomar às mãos as regras a que se submeter para dar a si mesmo uma vida.

\subsection{As difusões do poder}

A segunda estratégia de afirmação do capital, efetivada pela política empresarial, em nosso entender, atualiza-se na multiplicação das instâncias de efetuação das relações de poder. Como salienta Foucault (1995a), ao contrário de um tipo de poder concentrado nas mãos do soberano, como nos séculos XV, XVI e XVII, desde o século XVIII temos uma difusão das relações de poder entre diversas instâncias sociais: instituições, indivíduos, grupos, saberes, valores morais, técnicas etc. Nesse caso, as relações de poder dessas práticas empresariais de responsabilidade social são exercidas de maneira compartilhada entre várias instituições, tais como: educação, arte, psicologia, direito, medicina, biologia etc. A eficácia das relações de poder está na disseminação de um quantum de poder entre os indivíduos, dentro de um plano geral. As diversas estratégias de governo, na circulação de bens de capital, investem na condição de o indivíduo exercer um poder sobre si mesmo e sobre a ação de um outro, ou seja, agir sobre a ação de outrem, no governo das condutas. Todavia, essa estratégia não é exclusiva da política empresarial, porém é exercida com o Estado, o qual partilha ou articula as relações de poder com uma série de instituições, saberes, técnicas, táticas, valores e, em nosso caso, com as organizações-não-governamentais (ONGs), com os institutos sem fins lucrativos, ou o que se denomina, de forma geral, como o Terceiro Setor.

Nessa parceria entre as ONGs, Institutos, Universidades e o Estado, afirmam-se novas realidades sociais e, consequentemente, novas estratégias e táticas metodológicas como, por exemplo, a democracia participativa e o exercício da cidadania, as formas de legitimidade da autonomia e os direitos humanos etc., no seio das quais novas modalidades de exercício de poder são disponibilizadas ao seu público-alvo, em troca de novas ações das tecnologias de controle social.

A grande inovação dessas tecnologias é a criação de mecanismos de controle da população e de instrumentos com base nos quais ela irá controlar a si própria. Quer dizer, a população, como objeto técnico-político de governo, deve indicar os pontos de flutuação entre a escassez e a abundância dos fluxos de riqueza, em sua própria realidade, pois esses pontos da curva de normalidade são, em geral, justamente as possibilidades de intervenção econômica, de gestão de formas de governo e de intensificação das práticas a partir das quais a população terá condições de produzir o controle de si mesma. Incluem-se, nesse aspecto, os estudos do IBGE, a estatística, a demografia, a geografia humana, a cartografia, a economia, a saúde pública etc. 
Em resumo, para exercer o poder com eficácia, os fluxos de capital mundial precisam multiplicá-lo, expandi-lo de tal maneira que possam circular no interior das redes sociais sem interditos. Para tanto, os enunciados e as práticas que a política empresarial promove têm sempre uma natureza afirmativa, produtiva, pois a população precisa estar acessível aos agentes e às técnicas de transformação social.

Nesse sentido, a política empresarial de responsabilidade social introduz alguns procedimentos racionais que efetivam tanto a expansão do capital, quanto a eficácia do controle sobre a distribuição das riquezas.

\subsection{1 - O procedimento que incorpora os padrões da pesquisa científica}

Como exemplo, tomamos uma ação da política de intervenção empresarial efetivadas pelo já citado Instituto de Cidadania Empresarial de São Paulo e denominada Observatório Social de Jovens - real panorama da comunidade (INSTITUTO DE CIDADANIA EMPRESARIAL, 2005b). Nas atividades do observatório, é proposta aos jovens a realização de uma pesquisa sobre os problemas de uma comunidade da periferia pobre de São Paulo. Essa proposta fundamenta-se, entre outras coisas, no fato de que a:

[...] nossa sociedade se tornou uma sociedade da informação. Uma boa quantidade dessas informações provém dos resultados de pesquisas. Quantas vezes na vida escutamos: "a pesquisa demonstrou que..." Enfim, aprender sobre pesquisa nos ajuda a ser consumidores conscientes, bem como eventuais produtores de pesquisa. (INSTITUTO DE CIDADANIA EMPRESARIAL, 2005b, p. 9).

Do mesmo modo, trata-se de:

[...] inquietar-se constantemente "fazendo perguntas para o mundo", buscando conhecer melhor o funcionamento das coisas, promovendo aprendizagens, possibilitando o prazer de descobrir e compreender, e ampliando nossas possibilidades de intervenções. (INSTITUTO DE CIDADANIA EMPRESARIAL, 2005b, p. 8, grifo do autor).

A prescrição desse projeto é qualificar os jovens para a vida profissional, não apenas como possíveis pesquisadores sociais, que tomam as práticas científicas como norteadoras de suas ações na comunidade em que vivem, mas também como indivíduos capazes de analisar e resolver as situações que a vida cotidiana oferece.

Esse propósito investe em um tipo de ação que objetiva provocar no jovem o desejo de mudança, desejo este concebido como um universal natural do homem e o motor de sua ação, constituindo, justamente nessa naturalização do desejo, a marca, ou melhor, a porta de entrada da técnica governamental: a gestão da liberdade, isto é, deixá-lo atuar dentro de certos limites que estejam em acordo com certas conexões que combinem com o interesse geral da população. Como 
ressalta Foucault (2008a, p. 96), ao mencionar a produção "do interesse coletivo pelo jogo do desejo: isto marca ao mesmo tempo a naturalidade da população e a artificialidade possível dos meios que se instrumentalizaram para manejá-la".

Qual é a tática que se apresenta nessa perspectiva do Observatório Social? A produção de campos de saber sobre o homem e a gestão de instrumentos de orientação das condutas: como capacitar o jovem, como desenvolver certas habilidades e competências para que este venha a propor as ideias, as condições e os procedimentos necessários para a transformação de seu habitat e, consequentemente, realize a crítica e o juízo de si mesmo e de seus pares, a fim de produzir um olhar mais crítico e investigativo. "Fazer com que os jovens comecem a olhar para o que é aparentemente natural e corriqueiro e enxerguem o que lá se esconde. Desejamos despertar sua inquietação e a vontade de transformar o que deve ser transformado" (INSTITUTO DE CIDADANIA EMPRESARIAL, 2005b, p. 8).

Todavia, conforme aponta Michel Senellart (1995), em seu texto "A crítica da razão governamental em Michel Foucault", no momento em que Kant (séc. XVIII) desloca as condições da crítica para as formas do saber, ele neutralizou os seus efeitos políticos, mas também instituiu um novo front estratégico para a filosofia interrogar a matriz da razão política moderna. Trata-se de um acontecimento histórico que propiciou o desenvolvimento de uma ciência positivista, uma nova forma de poder estatal e, entre ambos, a emergência de uma ciência de Estado.

O que está em questão para o autor é que não basta a análise das práticas despóticas do Estado, mas que a crítica deve interrogar a própria racionalidade de governo como uma força viva, a qual distribui as materialidades sociais. Mais ainda, a atitude crítica não pressupõe a existência de um sujeito pleno da consciência de si mesmo, uma vez que ela "[...] não é da ordem de um juízo que sobrevoa a realidade histórica do alto de uma posição ideal de verdade. Procede das crises que atravessam a espessura de uma racionalidade, em suas múltiplas dobras" (SENELLART, 1995, p. 6).

Essas funções táticas apresentadas pelo Observatório Social partem do pressuposto moderno de que a realidade é um dado empírico natural, e os fenômenos inerentes a ela possuem uma regularidade passível de análise e de cálculo; desse modo, a realidade está acessível a um saber, para ser desvendada e transformada. Por meio de uma grade de interpretação do real, que se lhe ocultava, ao jovem favelado estão dadas as condições afirmativas da proposição de mudanças no cotidiano da comunidade em que vive, de sorte que o projeto, ora apresentado, realiza uma maneira de produzir jovens dispostos a pensar e a resolver os problemas que os afligem.

Entretanto, o que essas táticas instruem é um jeito de operar as relações de poder, a fim de que seu exercício seja, econômica e politicamente, o menos custoso possível, que seus efeitos tenham abrangência e intensifiquem a utilidade e a docilidade dos indivíduos, pois sem alguma espécie de fixação, quer a uma identidade ou a um grupo, o controle e a distribuição racional da população em 
larga escala frente às demandas do capitalismo seriam impedidas (DREYFUS, RABINOW, 1995). No projeto exposto, o que se efetiva é um modus operandi em que a lógica científica substitui os modos de agir das relações políticas e das práticas de enfrentamento que lhes são inerentes, ou seja, aquelas que dizem respeito à administração da vida cotidiana.

Se para esse homem a liberdade é vivida como um diálogo exclusivo consigo mesmo, como livre-arbítrio, como um fenômeno da vontade, supõe-se que a região legitimadora da liberdade seja da ordem de um domínio interno da consciência, a partir do qual as decisões serão tomadas. Contudo, como diria Hannah Arendt (1992), a liberdade vivida como um sentir interior não tem significação política. Para que ela possa se manifestar, necessita-se de um mundo publicamente organizado para que as instituições políticas possam realizar suas obras e o homem possa nelas se inscrever por atos e palavras. Sem um lugar factível no mundo, o homem não se manifesta, e um mundo refém de interesses privados não se efetiva como fenômeno político aberto às realizações humanas.

Se vivemos em um mundo em que, como diria Foucault (1995b), a matéria relevante para o julgamento moral são os sentimentos e toda ação só é crível se revelar os conteúdos internos que lhe dão forma, este homem seguirá enredado em complexos de saber/poder que pretendem ajudá-lo a descobrir sua verdade. Para reverter esse sistema de regras, faz-se necessária a construção de uma moral com acento na ética, e não em códigos morais baseados em dogmas teológicos ou enunciados científicos que legitimam certos modos de viver, mas sim que explicite uma atitude frente à existência: inventar formas de experimentar a si próprio a fim de fabricar-se, que não diz respeito a um exame da consciência, mas a determinar o que se pode ou não fazer consigo mesmo. Uma existência dedicada a pertencer-se a si mesmo frente ao outro, e ao mundo, onde se é convocado a designar seu próprio valor por meio das ações que o singularizem e a afirmar a independência de que se é capaz.

Nessa metodologia do Observatório Social, as relações entre o jovem e a comunidade são mediadas por práticas científicas, enquanto a comunidade é tomada como um objeto de estudo, como um dado de pesquisa. De um lado, a ação é pedagógica: ensina-se aos jovens pobres um estilo de intervenção baseado na ciência e na produção de regimes de verdade que as práticas capitalistas realizam sobre as condições da pobreza e da riqueza, na sociedade atual e, em específico, de certa localidade considerada de risco. Isso se processa de tal maneira que essas práticas científicas se efetivam como um novo mediador entre a relação dos jovens consigo próprios, com os habitantes entre si e o território em que vivem. Por outro lado, proporciona-se uma aproximação e um conhecimento neutralizado da comunidade, naturalizando seus problemas na ordem dos cálculos legitimados pela garantia de aval de um conhecimento de pesquisadores e cientistas. E, por fim, busca-se tratar um problema de ordem econômica e política de distribuição de riquezas, de modo distanciado, despolitizado, amenizando as paixões e os possíveis nichos de rebelião. 
Podemos dizer que essa metodologia empresarial traz uma estratégia de operar da ciência que, historicamente, exerce um papel explícito na produção de racionalidades extremamente violentas ${ }^{3}$, as quais agem no interior de um campo de neutralidade e proporcionam às relações de poder um tipo de eficácia menos evidente e, assim, as liberta para exercer o domínio e a governança, nas mais variadas formas do homem de trabalhar, de falar e de viver.

O que precisamos considerar, nesses procedimentos, é a eficácia desse modus operandi da ciência, que se guarda na neutralidade de seus procedimentos e de seus métodos e se revela subserviente às forças de poder em jogo. Nesse aspecto, o que se afirma, em uma proposta como essa do Observatório Social, é um ideal de ciência que se mostra ambíguo, pois, ao mesmo tempo em que se diz emancipatório, ele extingue, ou melhor, legisla as fronteiras entre a esfera pública e a privada, ao estender a técnica ao mundo das relações humanas e por realizar uma visão totalizante da sociedade.

Portanto, se as novas técnicas de governo instituem a atitude crítica no eixo da governamentalidade, isto é, na gestão das circunstâncias sob as quais se pode ser livre, as formas de exercício dos processos econômicos vigentes em nosso tempo histórico não proporcionam a emancipação, porém instituem um individualismo instrumental - o capital humano - que garante a produção da liberdade de que se precisa para bem governar (SENELLART, 1995).

Se a ética é esse campo de relação consigo mesmo que objetiva a criação ininterrupta de si próprio, essa experiência exige interrogar certos princípios desse operador em análise: a que modo de existência se aspira quando se pede aos jovens para "inquietar-se" frente às coisas do mundo em que vive? Esse ato e esse discurso objetivam a produção de um outro diferente daquele que já se é? Aspiram a produção de uma atitude frente à existência em que este homem possa alojar-se?

Incapaz de produzir um saber universal dos modos de operar dos processos econômicos na composição dos interesses, as formas de governança presentes na atualidade não controlam a engenharia dos interesses privados, por desconhecerem como e em que eles concorrem com o interesse geral. O que está em jogo, nesse embate de forças, é a multiplicidade não generalizável dos sujeitos econômicos e a unidade totalizante do Estado, de sorte que, nesse enfrentamento, há que se governar a produção da liberdade com limitações, com intervenções governamentais e possíveis ameaças da sua destruição. Um problema de segurança, enfim, para as táticas de governo, é a necessidade de calcular os índices de variação dos custos da fabricação dessa liberdade, já que a medida justa depende das relações entre governantes e governados. A lógica da estratégia é, por consequência, estabelecer conexões entre termos heterogêneos, de tal forma que entrem na ordem dos cálculos dos interesses, tanto a utilidade dos indivíduos como a independência necessária dos governados.

Todo esse modo de funcionamento das relações de poder promove a governamentalização do Estado pelos mecanismos de segurança afinados com os interesses variados das práticas econômicas vigentes. Um sistema de equilíbrio mundial das flutuações dos fluxos econômicos obriga os Estados a oferecerem a 
si mesmos um conjunto de objetivos que os limite, seja na política externa, seja na interna. E as técnicas necessárias para a pontuação e o cálculo desses limites têm a população como objeto tecnopolítico (FOUCAULT 2008a, 2008b), por ela ser um conjunto quantificável, fonte de riqueza, força de trabalho e de guerra, e, sobretudo, por ser suscetível a desvios e aberta aos mecanismos de intervenção. Nesse mesmo sentido, o conhecimento passa a ser desenvolvido no intuito de criar capital humano, tecnologias para o mercado e para a gestão da população, uma vez que é preciso conhecer as necessidades e as variáveis que a afetam, quer dizer, gerir os riscos. Por conseguinte, são as forças do mercado que têm a tarefa de realizar as conexões entre a economia política (um regime de verdade), a prática governamental e o governo.

Nesse operador, os modos de ação da política estão constrangidos às urgências e exigências econômicas vigentes e às possíveis reivindicações que delas derivam e, incitam formas de existência formuladas nas tecnologias políticas de governo dos corpos e, nesse âmbito, são os procedimentos de gestão dos riscos e os sistemas de verdade a eles conectados que serão acionados.

\subsection{2 - O protagonismo juvenil como critério de ação governamental}

Para a política empresarial, a responsabilidade social das empresas é uma das estratégias de multiplicação dos efeitos de poder e de gestão de risco, e, portanto, age no interior dos dispositivos de segurança. Como exemplo, pode-se destacar outra tática proposta pelo Observatório Social que se denomina de protagonismo juvenil.

O protagonismo juvenil está inserido em várias plataformas de procedimentos dessa política empresarial que visa ao "apoio e operação direta de projetos e programas de desenvolvimento comunitário, com foco na juventude" (INSTITUTO DE CIDADANIA EMPRESARIAL, 2004. p. 5). Entre esses programas, encontra-se um projeto social chamado Casulo, desenvolvido na região sudoeste do município de São Paulo, uma área "repleta de contrastes sociais, com favelas e prédios de luxo convivendo lado a lado" (PORTAL, 2005). A missão social desse projeto é "contribuir para a melhoria da qualidade de vida da população do Real Parque e Jardim Panorama, por meio de um processo de desenvolvimento comunitário que prioriza o jovem como agente estratégico de transformação social" (INSTITUTO DE CIDADANIA EMPRESARIAL, 2005a, p. 5), propondo-se como objetivo promover a autonomia e a cidadania da comunidade, por meio de ações de cultura e educação. O projeto existe desde 2003 e atende anualmente a cerca de 540 adolescentes e jovens, entre 12 e 24 anos, em situação de vulnerabilidade social.

Assim, um dos principais pontos de apoio da metodologia do Casulo é o protagonismo juvenil. Essa metodologia inclui os seguintes conceitos de sustentação: a autonomia, a cidadania, o desenvolvimento comunitário, o jovem como agente estratégico de transformação social e a cultura e a educação como instrumentos ou meios para realizar tal tarefa. O Empreendedorismo Jovem teria funções definidas: "Estímulo, capacitação e suporte aos jovens para a implantação de empreendimentos sociais e de geração de renda" (INSTITUTO DE 
CIDADANIA EMPRESARIAL, 2004, p. 11). Nessa estratégia, os jovens são aqueles que formarão a base da mão de obra para a ação comunitária, a qual tem por intuito o fortalecimento:

[...] das organizações de base comunitária locais, por meio de ações que contribuam para a viabilização de novos ativos, formação de lideranças e agentes sociais, bem como possibilitar a implementação de projetos que favoreçam o desenvolvimento socioeconômico da região. (INSTITUTO DE CIDADANIA EMPRESARIAL, 2004, p. 11).

Esse projeto incentiva o trabalho político do jovem, no entanto, o domínio do campo político empreendido realiza a presença do jovem como um meio, ou melhor, como um instrumento de resolução dos problemas imediatos vividos no território, estimulando a formação do jovem como um ser consciente de sua participação social, no âmbito de um registro político: o homem concebido não apenas como força de trabalho, porém como um ativo de desenvolvimento de capital humano na construção do lugar onde habita. Por isso, a importância dada à capacitação profissional, ao suporte e ao estímulo às ações comunitárias organizadas por esses jovens.

Diante disso, questionamos: o que quer essa tática da política empresarial, quando toma o jovem como protagonista das ações sociais? Em que circunstância se faz necessário usar o jovem como ferramenta dos processos de mudança social? Segundo os representantes dos projetos sociais, "em virtude da notória escassez de políticas públicas que os contemplem, da falta de perspectivas na sociedade atual e das potencialidades ainda pouco valorizadas desse segmento etário" (INSTITUTO DE CIDADANIA EMPRESARIAL, 2004, p. 14).

Analisemos melhor esse argumento sobre a escassez de políticas públicas para os jovens. Hoje, temos disponível uma série de críticas feitas às práticas de governo do Estado em relação à sua negligência como órgão responsável pela formação e gestão dos procedimentos de organização dos fenômenos inerentes à população, de sorte que são inúmeros os estudos sobre a situação de vulnerabilidade e risco da juventude pobre e sobre o mau funcionamento ou o fracasso das ações estatais. Isso se baseia no fato de a faixa etária dos jovens se encontrar em um limiar das ações do Estado; há um vazio na rede de atenção social em relação a eles. Os jovens ocupam uma faixa etária que não lhes permite ficar sob a guarda das instituições (Creche, Escola, Orfanato) que o Estado oferece, mas também não têm a permissão de entrada no mundo adulto, do trabalho, pois este se lhes apresenta como um já realizado. Nesse sentido, os projetos sociais servem como táticas para os dispositivos de segurança, a fim de criar perspectivas mais promissoras frente a um destino sem redenção ou, como sustenta Zygmunt Bauman (2005), em Vidas desperdiçadas ${ }^{4}$, essas práticas se efetivam como contêineres de resfriamento do refugo humano, para que os jovens fiquem esperando a sua vez. Pode ser que esperem para sempre, pode ser que os mais impacientes entrem para ao mundo do crime e consigam um lugar em outras instituições, como a FEBEM ou a prisão. 
Para refletirmos sobre o outro argumento exposto - "a falta de perspectiva na sociedade atual" -, tomaremos outra análise de Bauman (2005). Segundo o autor, há um maior número de diagnósticos de depressão em pessoas nascidas na década de 1970 do que nas nascidas em épocas anteriores, e que esse fato se liga ao desemprego. Entretanto, Baumam (2005) esclarece que a depressão não se relaciona exatamente com o problema de desemprego, mas sim com uma espécie de redundância presente no mundo social. A situação de desemprego, no período anterior à 1970 era momentânea, de sorte que o destino do desempregado era o de um dia ter um emprego, era uma reserva de mão de obra; hoje, o destino do redundante é o refugo, o lixo. $\mathrm{O}$ desempregado tinha a função de equilibrar as curvas de normalidade dos processos de produção e circulação de riquezas; o redundante é apenas o excesso, é aquele que foi feito a mais - não é que ele seja defeituoso e não funcione bem, contudo, ele simplesmente foi feito a mais, igual a ele há muitos. Além disso, hoje, há uma falência, isto é, há flutuações de todas as fórmulas e receitas para a admissão no mundo do trabalho. Até a década de 1970, as regras de funcionamento e de composição do mundo do trabalho eram mais definidas e tinham uma durabilidade razoável, mas, na atualidade, essas regras têm uma validade provisória, de acordo com a utilidade necessária aos fluxos e às flutuações de mercado 5 .

Em relação aos argumentos apresentados pela política empresarial de capital social, que inscreve o jovem como um instrumento de desenvolvimento comunitário, a fim de otimizar as "potencialidades ainda pouco valorizadas ou exploradas dos jovens pelos projetos sociais", podemos levantar algumas questões. Primeiramente, vamos pensar nos projetos estatais de governo das condutas para essa categoria da população: os jovens. Para estes, o jovem, como ser de direito da Constituição, é o público-alvo do acesso aos bens sociais, culturais, da Educação ampla, de diversas atividades de lazer, esporte, trabalho, cursos profissionalizantes, saúde etc. Nesses projetos, se compreende o jovem como um cidadão, como corpo em desenvolvimento e formação de seu capital humano; portanto, o trabalho com os jovens é imanente às formas de governo do Estado e das forças sociais que organizam a sociedade em que vivemos. Nos projetos sociais da política empresarial, busca-se uma responsabilização do jovem pelas mudanças que se quer fazer, na comunidade e na sociedade, tornando-se o jovem um dos meios pelos quais se realizam as transformações sociais. Todavia, é possível imputar tal responsabilidade ao jovem? O mundo adulto, público, responsável pelos negócios humanos e mundanos faz o quê?

Como já frisamos, atualmente, os jovens em geral não estão inscritos na ordem do trabalho; em especial, a juventude pobre, nesse sentido, deve-se ocupálos com qualquer coisa, para que esse estado de perambulação da pobreza atinja os limiares das curvas de normalidade, ou seja, passível de governo e, assim, as circunstâncias possíveis de rebelião entram na ordem dos cálculos de gestão da liberdade. É uma questão de segurança. Se não há trabalho nem para alguns adultos, entretêm-se os jovens com atividades autorreferentes, as quais se esgotam em si mesmas, isto é, apesar de se dizer que esses projetos sociais efetivados pela política empresarial preparam os jovens para a vida contemporânea, que exigem 
pessoas criativas, produtivas e políticas, que saibam organizar seu espaço e viver em grupo, ou seja, desenvolver o capital humano e social; essas atividades frequentemente se inscrevem no interior dos cálculos precisos de custos econômicos e de uma racionalidade específica de governo da série escassez-abundância. Os jovens continuam vivendo em favelas, agora higienizadas e inscritas em um registro de estetização da pobreza.

\subsection{3 - A metodologia participativa como critério de ação governamental}

Finalmente, como terceiro procedimento da estratégia de expansão dos modos de efetuação das relações de poder, a política empresarial terá em vista a produção de formas de enunciação e de campos de visibilidade desse modo de viver da pobreza, a partir de procedimentos denominados de metodologias participativas. Para ilustrar esse investimento das relações de forças, tomaremos novamente como exemplo os trabalhos do Observatório Social.

"Desenvolvido pelos jovens, o Observatório Social produz, analisa e fornece dados e indicadores que subsidiarão a implementação de ações sócio-educativas [sic], projetos de intervenção local e a proposição e monitoramento de políticas públicas" (INSTITUTO DE CIDADANIA EMPRESARIAL, 2005, p. 15).

Trata-se de um tipo metodologia participativa que pesquisa um território específico e, com base nos resultados, propõe intervenções e monitoramento, tendo como atores os jovens do local. Constrói-se integralmente com a intervenção e a participação dos jovens, responsáveis pelo levantamento de dados, por meio de pesquisas de campo sobre as condições socioeconômicas da região onde o Casulo atua. Mais ainda, é de responsabilidade desses jovens a realização da análise dos dados obtidos e a proposição e a execução dos projetos.

A primeira vantagem para os idealizadores desse instrumento metodológico é a de que, por contar com a participação do jovem, em todas as etapas, se pode promover ações fundamentadas em dados considerados mais precisos, já que as pesquisas são feitas pelos jovens da própria comunidade, pois há o pressuposto de que eles a conhecem muito bem. Visto que são realizados estudos específicos para um determinado território, em vez de manusearem os dados mais gerais, como os do IBGE, utilizam os dados das pesquisas realizadas pelos próprios jovens que participam do Observatório Social, pois estas são tomadas como condição de expressão da realidade específica da região.

Em lugar de usarem os instrumentos de análise da população feita pelo Estado, a política empresarial, por intermédio do estatuto de metodologia participativa, cria uma forma de gestão baseada em seus próprios princípios de intervenção, que leva a uma otimização e barateamento dos custos de suas ações e ainda a adiantar, em uma fase, o processo do projeto. De maneira geral, as atividades de intervenção social possuem as fases de planejamento, pesquisa de campo, montagem das ações, execução, monitoramento e avaliação e, normalmente, nas práticas estatais, a participação do público-alvo se restringe à fase de execução e, no máximo, à de avaliação. Entretanto, notamos que, no projeto Observatório Social, a participação do público-alvo, o trabalho sobre o corpo do jovem - a moldagem 
desse corpo, dentro de uma lógica específica de funcionamento das estratégias de poder do capital - inicia-se logo na primeira fase do processo, no planejamento das ações. Os jovens participam de todas as fases do processo de intervenção comunitária. Eles planejam, pesquisam, organizam as ações, executam, monitoram e avaliam o processo, juntamente com os coordenadores das ONGs.

Entendemos que, com essa iniciativa, esse operador ativa certos índices de governança das condutas, sejam elas econômicas, sociais ou subjetivas; colocando-as na ordem dos cálculos dos interesses que intensificam a utilidade dos indivíduos e dos custos dos projetos. Na fase de pesquisa de campo, não é mais necessário gastar com o pagamento de pesquisadores profissionais; na fase de montagem das ações, apropria-se de um elemento caro a esse tipo de projeto: a criatividade juvenil para a formulação de atividades. Também não há despesas com a fase de execução, porque se emprega a mão de obra gratuita do jovem. $\mathrm{Na}$ avaliação da eficácia do projeto, não há exatamente uma precarização dos custos econômicos, porém uma resolução de compromisso: caso a atividade não obtenha êxito, isso não é um grande problema, porque o mais importante é o processo de construção. Os jovens devem aprender que "nem tudo na vida dá certo", que o essencial é o processo de aprendizagem, além de que a "culpa" por conta de um eventual fracasso não recai apenas sobre a instituição responsável, mas também sobre as possibilidades proporcionadas pela metodologia. Assim, os projetos sociais da política empresarial têm, gratuitamente, aquilo pelo qual, antes, os projetos estatais pagavam, além de receberem votos de excelente prática educativa e de apoio ao desenvolvimento local, já que, ao contrário de se trazer especialistas, formam-se as pessoas da própria comunidade.

As estratégias afirmativas do mercado de capital absorveram as críticas feitas ao Estado e ao seu modo de operar a política assistencial, isto é, de que essa política forja a assistência no interior de um tipo de governo baseado nas práticas de cuidado, de bem-estar e, portanto, ela não desenvolve a autonomia e se inscreve no registro do que se poderia chamar de excesso de governo.

Uma dessas críticas é a de que o Estado aplica, em seu objeto técnicopolítico, à população, as tecnologias que não são aceitas por ela, que não têm efetividade, afinidades e tampouco são perenes, pois não há participação da comunidade, em sua construção e execução. De acordo com essas críticas, o Estado, quando intervém em um determinado elemento da realidade, é ineficaz sob alguns aspectos: em primeiro lugar, ele não divide ou delega o poder às pessoas da comunidade, na realização dos projetos; em segundo, não efetiva bem as etapas de realização da pesquisa, porque os executores dessa tarefa não pertencem à comunidade e, logo, não traduzem bem seus anseios; e, em terceiro, se gasta muito no pagamento de especialistas, em vez de acreditar no potencial da população que se quer melhorar ou transformar. 


\section{Conclusão}

Nesses três procedimentos analisados - a pesquisa científica, o protagonismo juvenil e a metodologia participativa -, existe um status de inovação metodológica que devemos interrogar. Inicialmente, deve ser levado em consideração qual regime de saber tal tática estimula, e em função de quais interesses se quer mudar os destinos da população. Além disso, como delegar um tipo de poder aos indivíduos, de tal forma que este atue sobre eles mesmos? E, por fim, quais relações de força estão em jogo quando se propõe aos indivíduos que orientem sua conduta e do restante da população a partir de um conjunto de regras que sustentam certo modo existir,

Mais ainda, devemos nos questionar: qual o saber que se produz a respeito da população que se quer transformar? A que relações de poder as práticas de capital social das empresas respondem quando enunciam essas transformações e delegam um quantum de poder a certos indivíduos de um território?

Desse modo, ao expandir e multiplicar os pontos de conexões da rede de relações de poder e de produção de saber com aqueles sobre os quais incidem as artes de governar, os fluxos de capital produzem novas exigências políticas de regulamentações sociais, tanto em relação àquelas dirigidas ao Estado, quanto às eventuais flutuações dos elementos de realidade que compõem os fenômenos do binômio escassez-abundância de riquezas. Assim, é possível obter um controle da população sem que a ação do poder lhe seja exterior, como também se torna possível intervir sobre os riscos de rebelião.

Essas estratégias e procedimentos da política empresarial de responsabilidade social, apresentadas neste ensaio, criam um dispositivo de controle social, no interior de uma série de linhas de enunciação e de visibilidade dos modos de viver dos indivíduos, responsável pela gestão dos interesses em jogo nos circuitos do mercado de bens de capital e da segurança de seus meios de circulação. Esse acontecimento desloca os interesses de uma rede empresarial globalizada para a esfera de relevância pública, quer aqueles relacionados à cidade, às riquezas, aos modos de funcionar e de se desenvolver o governo dos e entre os homens, quer os ligados à política que se exerce no eixo dessa lógica dos mercados e se oferece como partícipe das necessidades dessa rede empresarial global. 


\section{Notas}

${ }^{1}$ Sobre o conceito de governamentalidade, consultar: FOUCAULT, M. Segurança Território e População. (E. Brandão, Trad.). São Paulo: Martins Fontes, 2008a. p.143.

${ }^{2}$ Entre os resultados das ações de 2004 do Instituto de Cidadania Empresarial (ICE) está a presença da prefeita de São Paulo, à época (Marta Suplicy), e do ministro de Estado da Cultura, Gilberto Gil, em um evento de inauguração de um projeto do Instituto, o que mostra a potência política e econômica que esse tipo de iniciativa alcança.

3 "A racionalidade é o que programa e orienta o conjunto da conduta humana. Há uma lógica tanto nas instituições quanto na conduta dos indivíduos e nas relações políticas. Há uma racionalidade mesmo nas formas as mais violentas. O mais perigoso, na violência, é a sua racionalidade. É claro que a violência é, nela mesma, terrível. Mas a violência encontra sua ancoragem mais profunda e extrai sua permanência na forma de racionalidade que utilizamos. Pretendeu-se que, se vivêssemos em um mundo de razão, poderíamos nos livrar da violência. Isso é inteiramente falso. Entre a violência e a racionalidade não há incompatibilidade" (FOUCAULT, 2003. p. 319).

${ }^{4}$ No livro Vidas desperdiçadas, Bauman utiliza a metáfora do lixo para falar da nossa época. Os projetos sociais seriam como um contêiner resfriado, para que os problemas, advindos do refugo humano, não se espalhem pela sociedade (BAUMAN, 2005).

${ }^{5}$ Sobre esse assunto, ver também SENNETT, R. A corrosão de caráter: as conseqüências pessoais do trabalho no novo capitalismo. Rio de Janeiro: Record, 1999.

\section{REFERÊNCIAS}

ARENDT, H. Entre o passado e o futuro. 3. ed. São Paulo: Perspectiva. 1992.

BAUMAN, Z. Vidas desperdiçadas. Tradução de Carlos Alberto Medeiros. Rio de Janeiro: J. Zahar, 2005.

DREYFUS, H. L.; RABINOW, P. Michel Foucault: uma trajetória filosófica para além do estruturalismo e da hermenêutica. Tradução de Vera Porto Carrero Rio de Janeiro: Forense Universitária, 1995.

FOUCAULT, M. Microfisica do Poder. Rio de Janeiro: Graal, 1979.

FOUCAULT, M. Tecnologías del yo y otros textos afines. Barcelona: Paidós Ibérica, 1990.

FOUCAULT, M. Sujeito e Poder. In: RABINOW, P.; DREYFUS, H. L. Michel Foucault: uma trajetória filosófica para além do estruturalismo e da hermenêutica. Tradução de Vera Porto Carrero Rio de Janeiro: Forense Universitária, 1995a. p. 231-249.

FOUCAULT, M. Sobre a genealogia da ética: uma revisão do trabalho. In: RABINOW, P.; DREYFUS, H. L. Michel Foucault: uma trajetória filosófica para além do estruturalismo e da hermenêutica. Tradução de Vera Porto Carrero Rio de Janeiro: Forense Universitária, 1995b. p. 253-278.

FOUCAULT, M. Resumo dos cursos do Collège de France: 1970-1982. Rio de Janeiro: J. Zahar,1997. 
FOUCAULT, M. Foucault Estuda a Razão de Estado. In: FOUCAULT, M. Ditos e Escritos IV: Estratégias, poder-saber. Rio de Janeiro: Forense Universitária, 2003. p. 317-323.

FOUCAULT, M. A hermenêutica do sujeito. Tradução de Marcio Alves da Fonseca. São Paulo: Martins Fontes, 2004.

FOUCAULT, M. Segurança Território e População. Tradução de Eduardo Brandão. São Paulo: Martins Fontes, 2008a.

FOUCAULT, M. Nascimento da Biopolítica. Tradução de Eduardo Brandão. São Paulo: Martins Fontes, 2008b.

INSTITUTO DE CIDADANIA EMPRESARIAL. Metodologia para a formação de jovens pesquisadores: Observatório de jovens - Real panorama da comunidade, São Paulo: ICE, 2005. Disponível em: <http://www.ice.org.br>. Acesso em: 23 jun. 2007.

PORTAL do Voluntariado - A transformação do Casulo: Entrevista com Ivaneide Dantas da Silva. São Paulo: Portal do voluntário, 2005. Disponível em: $<$ http:// www.portaldovoluntariado.org.br>. Acesso em: 22 out. 2005.

INSTITUTO DE CIDADANIA EMPRESARIAL. Relatório de atividades 2004. São Paulo: ICE, 2004. Disponível em: <http://www.ice.org.br>. Acesso em: 23 jun. 2007.

INSTITUTO DE CIDADANIA EMPRESARIAL. Relatório de atividades 2005. São Paulo: ICE, 2005. Disponível em: <http://www.ice.org.br>. Acesso em: 23 jun. 2007.

SENELLART, M. A crítica da razão governamental em Michel Foucault. Foucault - Um pensamento desconcertante. Tempo Social: revista de sociologia da USP. São Paulo, v.7, n.1-2, p. 1-14, out. 1995.

SENNETT, R. A corrosão de caráter: as conseqüências pessoais do trabalho no novo capitalismo. Rio de Janeiro: Record, 1999.

Recebido em: 25 de setembro de 2009 Aceito em: 18 de maio de 2011 